\title{
Fostering Independent Learning amongst English for Academic Purposes Students through Exploration of Digital Tools
}

\author{
Marie-Claude Toriida \\ University of Calgary in Qatar, Doha, Qatar \\ Robert Johnson \\ University of Calgary in Qatar, Doha, Qatar \\ Simon Heslup \\ University of Calgary in Qatar, Doha, Qatar \\ Rabeena Adul Latif \\ University of Calgary in Qatar, Doha, Qatar \\ Conchita Fatima Chiuco \\ University of Calgary in Qatar, Doha, Qatar \\ Abdul Rahman Hamdeh \\ University of Calgary in Qatar, Doha, Qatar \\ Sharifat Atinuke Makinde \\ University of Calgary in Qatar, Doha, Qatar \\ Rubeena Toufiq \\ University of Calgary in Qatar, Doha, Qatar \\ Nooreh Mehdi Zadeh \\ University of Calgary in Qatar, Doha, Qatar
}

\begin{abstract}
Interest in using digital tools (DTs) to facilitate self-directed learning has continued to increase alongside the power and complexity of the Web. However, English language instructors cannot always be certain of the appropriateness of particular DTs for their students' unique linguistic needs, learning preferences, and cultural sensitivities. This study seeks to determine if a pedagogical approach making English language learners (ELLs) at a university in Qatar responsible for finding, trialing, vetting, and perhaps endorsing DTs results in significant changes in opinions and behaviours regarding such self-directed learning resource use. The analysis of the quantitative and qualitative data suggests that students in this context are already using DTs for English language learning, without prior teacher instructions, and are comfortable doing so. However, the findings suggest that students of lower English ability might benefit from more initial instructor guidance in selecting and using new DTs. While participants did not increase their use of DTs as a result of the intervention, they noted having become more efficient in using them. All participants said that the intervention had been beneficial. Many noted they had discovered at least one new tool that they would continue to use.
\end{abstract}

Index Terms - digital tools, language learning, self-directed learning, language learners, English for academic purposes, higher education

\section{BACKGROUND}

Independent learning as a means of improving student education has long been a topic of interest amongst educators. Moore (1973), known for his pioneering work in independent learning, suggested that by encouraging them to learn autonomously, outside of the classroom, teachers help students to develop both the ability and the will to exercise their own powers of learning, allowing them to attempt difficult learning tasks and overcome academic obstacles.

More recently, interest in using digital tools (DTs) to facilitate self-directed learning has continued to increase with 
the development of the power and complexity of the Web (Blake, 2013; Saxena, 2013). Amongst the important reported benefits of students' independent use of DTs are greater learner motivation (Saxena, 2013) and the development of learning communities outside the traditional educational setting (Lord \& Lomicka, 2011).

The standards developed by the International Society for Technology in Education to promote the effective use of technology in education state that educators should create a culture in which students assume responsibility of the goals and outcomes of their learning when working both individually and in groups (International Society for Technology in Education, 2017). Furthermore, students should be empowered to create both their own learning goals as well as technology-based strategies to achieve these goals, and then be encouraged to reflect on this process to improve future learning outcomes (International Society for Technology in Education, 2016). According to the standards, it is also important for educators to provide students with the opportunity to develop their understanding of fundamental concepts related to operating technology as well as their abilities to select and troubleshoot current technologies (International Society for Technology in Education, 2016).

For language learners, the Web 2.0 has often been used to provide added opportunities to practice or use language outside of the classroom (Blake, 2013; Borau, Ullrich, Feng, \& Shen, 2009). Examples include the litany of grammar explanations and practice exercises available online, and the well-documented use of microblogs for language learning (Antenos-Conforti, 2009; Castrillo De Larreta-Azelain, 2013; Lord \& Lomicka, 2011; Wang \& Vásquez, 2012).

Use of Digital Devices by University Students in Qatar

According to the most recent estimates, 93\% of Qatar's population are classified as internet users, and there are 169 mobile cellular subscriptions per 100 inhabitants (Central Intelligence Agency, n. d.). While little is known about how language learners in the region use these resources for self-directed independent language learning and what resources they find helpful, a limited number of studies have begun to explore this.

One survey of college students in Qatar asked about the digital devices they owned and what they used them for (MacLeod, 2015). Nearly all students reported owning a smartphone and a laptop, with many students owning multiple smartphones. Seventy-five percent of respondents owned a desktop computer, and more than half owned a tablet. However, only $63 \%$ reported using a digital device for study, and only 58\% believed that technology allowed them to accomplish more academically. The most commonly used devices for studying and getting information were laptop computers, and the most commonly used for communication and entertainment were mobile phones. While Macleod (2015) found nearly $80 \%$ of respondents reported their ability to use technology to be either expert or advanced, Alajmi (2011), in a study at a college in Kuwait, found students had limited awareness of Web 2.0 tools beyond the few tools that they used most often for personal reasons, and to rarely use Web 2.0 tools for learning. As a result, Alajmi (2011) emphasized the importance of training students to use digital tools for academic purposes.

A third study surveyed students at a university in Qatar regarding their digital devices (Fayed, Yacoub, \& Hussein, 2013). All participants had at least one smartphone, $28 \%$ had more than one, and $13 \%$ owned a tablet device. Participants were asked to give information regarding their usage of various smartphone features, including specifically for educational purposes. Most participants reported using their smartphones to contact family and friends through calls, texting, and social networks. Most participants also reported using their smartphones to listen to audio files, watch videos, and surf the Internet. Also mentioned, though less commonly, was using the smartphones to access documents and various apps. When asked about smartphone use for educational purposes, the most common responses were accessing the school learning management system, completing assignments, and using dictionaries. In subsequent interviews five of seven students stated they used their phone to learn English, and all participants preferred learning with a smartphone rather than books. Six of seven reported feeling motivated to learn with smartphone technology.

None of the above studies investigated the reasons behind students' selection of DTs for educational purposes. However, at a university in Qatar, the Unified Theory of Acceptance and Use of Technology was applied to investigate students' adoption of technology presented as part of university courses (Akbar, 2013). The Unified Theory of Acceptance and Use of Technology (UTAUT) is one of the most common models used to explain individuals' adoption of technology. In UTAUT, the adoption of a tool is based on a combination of performance expectancy (usefulness of the tool), effort expectancy (ease of use), social influence (perception that others believe the tool should be used), and facilitating conditions (the effectiveness of available technical support) (Venkatesh, Morris, Davis, \& Davis, 2003). Akbar (2013) found that, as predicted by UTAUT, performance expectancy, effort expectancy, and facilitating conditions had a significant influence on students' acceptance of technology (Akbar, 2013). Social influence was also found to have an effect (Akbar, 2013). Similarly, a study of university students' acceptance of learning through digital mobile devices in Iran suggested that performance expectancy influenced students' adoption of DTs (Chavoshi \& Hamidi, 2019).

While these studies provide a valuable start, there remains a substantial void when it comes to understanding what learning tools students in the Middle East (and Qatar) find useful and appropriate for independent language learning.

\section{THE PRESENT STUDY}

In English as a Foreign Language (EFL) environments, students typically do not spend much time functioning in English outside of the classroom. Therefore, they would almost certainly benefit from having added time using the language, especially if this added time easily fit their schedules, was culturally and linguistically appropriate, and was 
appealing to this generation of learners. Digital tools are one method through which such needs could be met. In the present study, a digital tool was defined as: Any program, app, or Internet site that a student uses through their computer, smartphone, or tablet. A better understanding of how language learners in EFL environments use DTs, and how DTs could be used more effectively to improve language skills via independent learning, would be of great importance for students and educators.

However, English language instructors cannot always be certain of the appropriateness of particular DTs for their students' unique linguistic needs, learning preferences, and cultural sensitivities. As a result, they may be hesitant to introduce, or be seen as endorsing, DTs which may turn out to be of limited value or perhaps even contain materials students might consider culturally insensitive. Consequently, a wealth of resources to support learners in the Middle East may be going unknown and unexploited. Our study was modeled after an alternative approach which made students responsible for finding, trialing, vetting, and perhaps endorsing DTs (Ohashi, 2015). As part of her doctoral dissertation, Ohashi (2019) studied the independent learning practices using DTs of first year university English majors in Japan. Students completed baseline questionnaires of DT use for English language learning prior to a ten-month English language course throughout which they were required to trial and report on DTs. The same questionnaire was administered at the end of the course, and again six months after the course had ended. Baseline data showed that students did not use DTs often for English studies although device ownership was high. Throughout the course, students were asked to set learning goals and to find, trial, and report on DTs to support their goals. They wrote reports of their tools on a class Facebook page. By the end of the course, there was a significant increase in the reported use of DTs for language learning. Data from the final questionnaire indicated a decline of DT use compared to at the end of course. However, this reported tool use for English studies still indicated a significant increase when compared to the baseline data.

Our study seeks to determine if pedagogical approach similar to the one described by Ohashi (2019) results in significant changes in the opinions and behaviours of ELL university students in Qatar regarding such self-directed learning resource use. The research questions guiding this study were:

1. What are the online practices of tertiary education students in an English for Academic Purposes (EAP) program in Qatar?

2. How are EAP students' independent learning practices influenced by participating in a course that requires them to use digital tools to develop their English skills?

3. On what basis do university students in Qatar select digital tools for language learning?

4. On what basis do university students in Qatar rate digital tools for English language learning?

\section{METHODS}

\section{A. Setting}

The study occurred at a transnational campus of a North American university, located in Qatar. The institution delivers bachelors (BN) and masters (MN) programs in nursing. All courses and support are offered in English. Language proficiency entry requirements include either an IELTS (academic) of 6.0 or iBT (internet-based TOEFL) of 80 or higher. Eighty-five percent of students, however, do not meet these requirements and complete Accuplacer ESL and a writing sample, for placement within the English for Academic Purposes Program (EAPP) program. The EAPP has three tiers, each representing one term of study, and students are expected to complete the program within three terms.

\section{B. Participants}

The target population for the study was EAPP students at the institution. A total of 49 students were enrolled in the program the semester the study began, with 13, 19, and 17 in Tiers 1, 2, and 3, respectively. A total of 26 of these students agreed to participate in the study, with 8,9 , and 9 students in Tiers 1,2 , and 3 . While a sample size of 26 is small for a study comparing subgroups for potential treatment effects, it does represent over half of the target population at the time.

Demographic data indicate participants were generally representative of the student population, in terms of age (18 to $36, \bar{x}=22.62$ ), diversity (11 different nationalities, all from the Middle East \& North Africa region), and reported first languages (Arabic 23, others 3). While all participants were female, this was not considered significantly divergent from the $90 \%$ female student population.

Twenty-two participants were regular track (RT) students and 4 were post-diploma (PD). RT students have no nursing credentials and complete the entire four-year BN program. PD students have a diploma in nursing and complete two years of study to attain their BN. While the current ratio of RT:PD students at the institution approximates 1:1, the recent trend towards intake of high school graduates at the institution means far more RT students in the EAPP program. As such, the predominance of RT participants was considered reflective of the target EAPP population.

In an attempt to limit the extent that English language abilities of the different groups might influence outcomes, the treatment group was made up of the lowest (Tier 1) and highest (Tier 3) ability levels. Tier 2 students comprised the control group. 


\section{Procedure}

The study employed a repeated measure, mixed method, explanatory sequential design. It was also quasiexperimental, as participants came pre-assigned to specific courses, and random selection/assignment was not possible.

\section{Treatment:}

Participants in the treatment group were in EAP courses that included digital tool assignments. These assignments required students to complete and submit the following every two weeks. First, they needed to identify an objective they wished to achieve with regards to improving English abilities, such as "improve academic vocabulary" or "work on passive voice". Students were encouraged to align their goals with elements covered in the course, but final selection was their decision. Next, they needed to search for, select, and trial a DT they believed would help with their goal. After spending two weeks using the tool, treatment participants completed a short report (Appendix A) on the benefits and limitations of the tool, how it contributed (or not) to their language learning goal, and its cultural appropriateness. This evaluation was uploaded to an online class discussion group. Students were encouraged to read each other's reports and reply with comments of their own, but only the reports were assessed and part of the course grade.

\section{Questionnaires:}

Treatment and control participants completed two questionnaires. The first (Appendix B) contained nine items addressing participants' attitudes and behaviours regarding DTs in general, and DTs specifically for the purpose of improving English abilities. The second questionnaire (Appendix C) contained 44 items representing specific functions for which DTs can be used. For each function, participants indicated how much time they spent using DTs in L1, and in English. The questionnaires were used to both establish a baseline (pre-treatment) for participants' attitudes and behaviours regarding DTs and DT use, and provide evidence regarding any treatment effects at post and follow-up stages. Cronbach alpha results for Questionnaire 1, at pre, post, and follow-up stages of the study $(\alpha=0.658,0.722$, and 0.684 , respectively), were all below the traditional acceptable level $(\alpha=0.8)$ for reliability. However, the small number of items on the questionnaire (9) and relatively small sample size must also be kept in mind. Reliability estimates for the longer Questionnaire 2 were found to be well above the traditional reliability threshold $(\alpha=0.901,0.858$, and 0.897 at pre, post, and follow-up), indicating strong internal consistency.

Focus group interviews:

The qualitative component of the study involved semi-structured interviews conducted at post and follow-up (appendices D and E, respectively). As per explanatory sequential design (Creswell, 2014), qualitative data collection was intended to provide more depth and clarity to quantitative outcomes regarding English language development, impact of treatment, and experiences with DTs.

\section{Analysis}

\section{Questionnaires:}

Inability to conduct random selection/assignment of participants increases the likelihood of pre-existing group differences prior to treatment. As a result, Analyses of Covariance (ANCOVAs) were used to test for group differences at post and follow-up stages. Use of ANCOVAs, with pre-treatment results set as a covariate, provides an estimate of group effects while controlling for any differences between the treatment and control groups which may have existed prior to treatment.

Student reports:

Students were asked to report on five digital tools. Not all of the 17 participating students completed all five. Each question students were required to answer for each tool received a total of 80 or 81 responses of the possible 85 . The data from the participant reports were coded to identify common ideas. Each concept was coded individually. Longer responses which included several concepts were broken down into the individual concepts. Responses from different participants that clearly indicated the same concept were paraphrased and grouped together. Ungrouped responses were then reviewed by the three primary researchers. For each of these responses, the researchers reached agreement and either grouped it into an existing concept or labelled it as a unique response. Unique responses were grouped and reported as other.

\section{Focus group interviews:}

The data from the focus group interviews was analyzed using consensual coding (as described by Schmidt, 2004). Each interview was listened to independently by the three primary researchers. Each researcher created their own categories for coding and independently coded each participant response. After coding independently, the three researchers met as a group to compare and discuss their coding of the responses. Through thorough comparisons and discussions, all coding was then agreed upon and finalized. Next, themes arising from the focus group participant responses were identified through further discussion between the three researchers.

\section{RESULTS AND DISCUSSION}

A. RQ\#1. What Are the Online Practices of Tertiary Education Students in an English for Academic Purposes (EAP) Program in Qatar? 
Questionnaire 1 (Appendix B) addressed participants' access to digital devices, frequency of use for academic and non-academic purposes, and attitudes towards DT use and language learning. Baseline results for digital device access (Appendix F) reveal that participants typically had 2 or more digital devices of their own. All participants reported possessing smartphones, $85 \%$ had computers, and 34\% reported owning a tablet. This is similar to the results reported by MacLeod (2015) and Fayed, Yacoub, and Hussein (2013), and suggests little cause for concern regarding whether or not students: (1) have access to DTs; or (2) are familiar with the devices upon which they operate. Individuals ranged widely in their reported use of these devices for academic and non-academic purposes (Appendix G). However, overall use for non-academic purposes, especially computers and phones, was considerable, with means of $1.85(S D=3.69)$ hour per day for computers, $6.11(S D=5.16)$ for phones, and $0.47(S D=1.37)$ for tablets. This is important to know, as it implies that, before intervention, participants used these devices a considerable amount, and therefore were likely comfortable using them, as well as common DTs. However, participants did not seem to use devices for academic purposes nearly as much, with means of $1.11(S D=1.121), 1.34,(S D=1.16)$ and $0.32(S D=1.00)$ hours per day for computers, smartphones, and tablets, respectively. It is worth noting here that participants reported using their smartphones for learning purposes more than computers.

Appendix $\mathrm{H}$ summarizes participant responses to items in Questionnaire 1 addressing attitudes towards language learning, DT use, and DT use for the purpose of language learning. Mean responses for all items ranged from strongly agree (1) to agree (2). Overall, prior to treatment, participants report being highly "motivated to improve [their] English" $(\bar{X}=1.31, S D=0.471)$ and frequently communicating with others about how they study English $(\bar{X}=2.00, S D=0.800)$. They were already comfortable with DTs $(\bar{X}=1.19, S D=0.491)$, wanted to use DTs in English $(\bar{X}=1.35, S D=0.485)$ and frequently did $(\bar{X}=1.81, S D=0.634)$. They also reported already being aware of many DTs for improving English $(\bar{X}=1.54, S D=0.647)$, reported using many of them $(\bar{X}=1.76, S D=0.523)$, and agreed with the statement they would like to find new tools for this purpose $(\bar{X}=1.54, S D=0.582)$.

Overall, EAPP students at the institution would appear to come to courses in possession of and familiar with digital devices, specifically smartphones and computers. They reported (1) being familiar with DTs and frequently use them in English and in L1; (2) using many DTs for the purpose of learning English; (3) discussing study methods with their peers; (4) wanting to find new DTs for English acquisition purposes. This suggests a higher level of familiarity and comfort with DTs compared with the findings reported by MacLeod (2015) and Alajmi (2011), and may reflect how digital technology continues to become more integrated into the lives of students in the Middle East. This also contrasts with Ohashi's (2019) findings regarding students in Japan. Few participants in her study reported using the Internet in class or independently at base (17\% for listening, 13\% for writing, 10\% for reading, and 9\% for speaking).

Questionnaire 2 (Appendix C) addressed the frequency participants used DTs for specific purposes (e.g., social media, games, news, etc.) both in L1 and in English. Results are summarized in Appendix I, along with results of tests of significant mean difference. For nearly all of the functions listed, whether in L1 or English, reported use ranged from never (0) to every day (4), indicating a wide variation in use amongst participants. For 18 of the 22 functions, participants reported using DTs in English more than their first language. Paired t-test results indicate this differential was significant for 5 functions: learning English $(t(21)=-6.236, p=.000)$, dictionary/translation $(t(21)=-4.688, p$ $=.000)$, lifestyle $(t(21)=-2.932, p=.008)$, health and exercise $(t(21)=-2.592, p=.017)$, and online presentation makers $(t(20)=-2.121, p=.047)$. Two functions were found to be used in L1 significantly more than English: news $(t(22)=3.867, p=.001)$ and religion $(t(22)=5.334, p=.000)$. It may also be worth noting a few specific functions that were used approximately equally in English as in L1 - social media, written communication with individuals, written communication with groups, and information searches. This contrasts with Ohashi (2019), who found DT use in English relatively rare prior to intervention.

These results suggest that EAPP students already use many DTs in English at fairly high frequency. It might not be surprising that DTs for English learning and other academic purposes are used more often in English than L1 in a university context where all courses are taught in English. With regards to lifestyle and health exercise tools, it may be that tools are more readily available in English than in Arabic. In the context of a very multicultural society such as the one the study was conducted in, services are usually rendered in English. DTs related to shopping and transportation are most likely designed with this in mind. With frequency for use of written communication for individuals and groups, social media, and information searches in English approximately equalling their reported use in L1, this could be exploited in English courses. Because students are already comfortable using these DTs in English, they can be readily used as platforms for tasks to facilitate language acquisition.

\section{B. RQ\#2. How Are EAP Students' Independent Learning Practices Influenced by Participating in A Course That Requires Them to Use Digital Tools to Develop Their English Skills?}

Researchers wished to assess whether completion of the Digital Tool Use assignment influenced participant attitudes towards and behaviours using DTs for language learning. To this end, analysis of covariance (ANCOVA) was used to test for significant differences between treatment and control groups on: i) reported use of digital devices for academic and non-academic purposes, ii) attitudes and behaviours regarding DTs use, and iii) frequency of DT use for various specific functions. Comparisons were conducted both at post-treatment (end of the semester of treatment) and follow-up (end of the subsequent semester). 
After controlling for any pre-existing differences between treatment and control groups, no significant difference between the two groups was found for overall digital device use, whether for academic or non-academic purposes. This result was found both at post and follow-up (Appendices J and K). Similarly, at post-treatment and follow-up, there were no significant differences found between treatment and control groups for any of the questionnaire items addressing attitudes and behaviours regarding DTs (Appendices L and M). At post-treatment one item - "I am comfortable using digital tools" - approached significance $(F(1,23)=3.726, p=.066)$. A further paired t-test revealed a significant result between pre- and post-test. Analysis of the data indicated a significant decrease in comfort with using DTs from pre- to post-test $\left(t_{\text {paired }}(16)=-3.497, p=0.003\right)$. Control participants showed no significant change. While participants still reported feeling comfortable using DTs $(\bar{X}=1.71)$, they were less confident than before treatment $(\bar{X}=1.18)$. However, at follow-up this difference no longer approached significance.

During the second focus group interview, participants were informed of this decrease in comfort level. They were asked if this surprised them. Tier 3 participants answered in the affirmative while Tier 1 (lower level) participants were not as surprised. Both groups generated many possible reasons for the decrease in comfort. These reasons included: (1) novel DTs were often more difficult to use than anticipated; (2) some required the user to subscribe; (3) free versions often had many advertisements that interrupted use; (4) searching for DTs took time; and (5) some DTs had multiple uses, not all of which supported their chosen goal.

Completion of the DT project did not significantly influence participants' DT use in English for any of the functions listed in Questionnaire 2. Nor did it impact use of English learning tools in L1. This was found at both post-treatment and follow-up (Appendices $\mathrm{N}$ and $\mathrm{O}$ ).

These results differ from those of Ohashi (2019), who found a strong increase in reported DT use right after intervention completion, and, while lower than after the course completion, a continued significant increase six months after intervention. A possible reason for this difference is that in our study, the baseline results indicated a much higher use of DTs for English learning than in the Ohashi study. As mentioned above, this might reflect a cultural difference. Using DTs for English learning may be more common in Qatar than in Japan. If so, required exposure to DTs would have less of an impact on future use of DTs by students in Qatar.

When asked to comment during focus group interviews on the lack of an increase in DT use between pre and postintervention, participants said they were not surprised by this finding. Some said that following the intervention, they continued using only the DTs they had been using before the intervention period and did not spend much time using new DTs. Other participants admitted that as the intervention progressed, they began to select tools which they were already familiar with. Finally, some claimed that they actually did increase time spent using DTs, but that they became more efficient at choosing apps which saved time. They felt these may have balanced out and resulted in no net increase in DT usage, based on time spent. This explanation implies that participants were independently searching for DTs prior to the start of the intervention.

The focus group interviews also explored the experience of participants during the intervention. They reported that they would have preferred a less structured approach to the assignment. Specifically, participants would have preferred to: (1) use digital tools only when needed instead of being a requirement; (2) have one goal instead of changing goals every two weeks; (3) continue to use one tool instead of changing every two weeks; and (4) have the instructor select and introduce an initial DT. Participants also reported that not all of the DTs were easy to use.

C. RQ \#3. on What Basis Do University Students in Qatar Select Digital Tools for Language Learning?

Language goals reported when selecting digital tools:

Table 1 provides a list of the language goals participants reported when selecting DTs. The emphasis on topics such as vocabulary, grammar, and writing, rather than speaking, would appear to reflect the nature of the EAP program.

TABLE I.

SuMMARY OF REPORTED GOALS WHEN CHOOSING THE Digital TOOL

\begin{tabular}{ll}
\hline $\mathrm{n}=17$; total number of reports $=81$ & \\
\hline Goal (area of English language to improve) & Number of Times Indicated \\
\hline Vocabulary & 25 \\
Grammar & 16 \\
Writing & 13 \\
Verb tenses & 8 \\
Sentence structure & 7 \\
Reading & 6 \\
Speaking & 4 \\
Paraphrasing & 2 \\
Punctuation & 2 \\
Spelling & 2 \\
Other & 2 \\
\hline
\end{tabular}

Reported reasons for choosing the digital tool

The reported reasons for selecting the DTs (see Table 2) appear to support the assertions of the UTAUT (Venkatesh, Morris, Davis, \& Davis, 2003). Social influence was the biggest factor, as indicated by the number of times recommendations by family or friends (27) and former teachers (8) were reported. This idea was repeated in focus 
group interviews by participants, especially those of lower English ability (Tier 1), who commented on the usefulness of other students' reports in finding new DTs. Some participants also reported discussing the usefulness of the DTs with their classmates. Eighteen reports of a belief the tool will help to improve English reflects the importance of performance expectancy, as predicted by UTAUT. Again as predicted, ease of use appears as the third most common (8) reason given for choosing the tool. As students were not supported in their use of the tools, the fourth UTAUT determinant of user acceptance, facilitating conditions - or the effectiveness of available technical support - was not reported. This supports the findings of Akbar (2013) and Chavoshi and Hamidi (2019).

TABLE II.

SUMMARY OF REPORTED REASONS FOR CHOOSING THE DIGITAL TOOL

\begin{tabular}{ll}
\hline $\mathrm{n}=17 ;$ total number of reports $=81$ & \\
\hline Reason & Number of Times Indicated \\
\hline Recommended by family or friends & 27 \\
A belief the tool will help to improve English & 18 \\
Looks interesting & 8 \\
Looks simple to use & 8 \\
Recommended by a former teacher & 8 \\
Saw the tool advertised online & 7 \\
Covers a range of topics / multipurpose & 3 \\
Visually appealing & 2 \\
I used it before & 2 \\
Other & 4 \\
\hline
\end{tabular}

\section{RQ \#4. on What Basis Do University Students in Qatar Rate Digital Tools for English Language Learning?}

\section{Ratings of digital tools:}

Participants reported using 53 individual tools. Most tools were favourably reviewed by participants, as indicated by the 3.56 and 3.54 out of 4 average ratings for usefulness and cultural appropriateness, respectively (see Appendix P). As with the large number of good points relative to bad points reported for the tools (see Tables 3 and 4), the favourable ratings may be attributed to participants experimenting briefly with the tools before selecting them (and thus not selecting tools they expected to be poor) as well as to participants selecting tools based on recommendations from acquaintances. As mentioned in the description of the assignment, students were required to trial DTs which they believed would be useful in helping them reach their learning goal. The high ratings of cultural appropriateness could suggest that there are few DTs available which may be considered culturally inappropriate to students in Qatar. It could also suggest that participants were usually able to identify culturally inappropriate DTs early on and thus avoid selecting them for trial.

Reported good points of digital tools:

The most common positive comments participants made about DTs are listed in Table 3. Students were asked to provide an explanation of how the tool helped them to reach their goal (if it did). They were also asked to provide any additional good points of the tool, as well as any bad points. Table $\mathrm{C}$ was compiled by combining the participant responses for "explanation" and "good points." If a participant provided the same response twice for a tool, the response was only recorded once.

TABLE III.

SUMMARY OF REPORTED GOOD POINTS OF DIGITAL TOOLS

\begin{tabular}{ll}
\hline$n=17$; total number of reports $=80$ & Number of Times Indicated \\
\hline Good Point & 48 \\
\hline Helped to improve English & 29 \\
Many exercises/examples/quizzes & 26 \\
Easy to use & 15 \\
Corrects errors / gives useful feedback & 18 \\
Fun/interesting / includes games & 14 \\
Does not require an Internet connection & 9 \\
Many/effective explanations & 8 \\
Personalized to target specific individual needs & 7 \\
Information on a variety of topics & 5 \\
Can translate to/from L1 & 5 \\
Free & 5 \\
Post-exercise quizzes to check skill acquisition & 5 \\
Accessible through mobile apps and online computers & 4 \\
Used online & 3 \\
Available in many languages & 2 \\
Has different levels of difficulty & 2 \\
Can type in Arabic & 2 \\
Easy to download & 2 \\
Fast & 23 \\
Other & \\
\hline
\end{tabular}


By far the most common positive comment was that the DT helped the participant to improve their English. Other frequent responses included praising tools that provided a large number of exercises or examples and commenting on tools that were easy to use.

Reported bad points of digital tools:

When asked to comment on a DT's bad points, the most common response participants provided was "no bad points" (see Table 4). This is possibly because participants were trying tools briefly before selecting them for use for the assignment, and thus only reporting on tools that they already had some positive feelings towards. Table B indicates that participants were selecting tools that either they had a least some familiarity with or had been recommended by an acquaintance. Of the bad points that were reported, required Internet connections, too much advertising, and slow response time were the most common. The list of bad points was compiled from the participant responses to the assignment question asking them to describe any bad points of DTs. Participants did not list bad points when asked to explain how the tool helped them to reach their language goal.

TABLE IV.

SUMMARY OF REPORTED B AD POINTS OF DIGITAL TOOLS

\begin{tabular}{ll}
\hline$n=17 ;$ total number of reports $=81$ & Number of Times Identified \\
\hline Bad Point & 17 \\
\hline No bad points & 12 \\
Requires an Internet connection & 10 \\
Too many advertisements & 8 \\
Slow response & 5 \\
App only, cannot use on computers & 4 \\
Not enough exercises or examples & 4 \\
Premium features are not free & 4 \\
There are language errors & 3 \\
Computer only, no app & 3 \\
There is a timer, requiring a quick response & 2 \\
Also includes mathematics exercises & 2 \\
Sign up required for some or all features & 2 \\
Not enough exercises or examples & 15 \\
Other & \\
\hline
\end{tabular}

In the focus group interviews, participants elaborated on some of the difficulties they had with the tools. Some participants reported that some DTs were difficult to use. Specifically, they mentioned the need for advanced English vocabulary to use the DT. They mentioned that not all students (especially older ones) were experienced using DTs. The desire for more teacher guidance in all aspects of the assignment (finding, selecting, trialling, and evaluating DTs) was also mentioned. This suggests that teachers cannot assume that all of their students are able to effectively select and use DTs beyond the ones that they are already familiar with.

\section{CONCLUSION}

This study contributes to the limited literature which considers the attitudes and practices of university students in Qatar and the Middle East regarding the use of digital tools for English language learning purposes. It is hoped that the findings of this study will be useful for educators who are considering the many factors involved in how to successfully integrate DTs into their courses. For example, teachers should be aware that students appear to be using their smartphones more often than their computers for academic use.

The analysis of the quantitative and qualitative data suggests that EAP students in this context are using DTs for English language learning without prior teacher instructions, and are comfortable doing so. While students did not increase their use of DTs as a result of participating in a course which required them to, they noted having become more efficient in using them. All students said that the intervention had been beneficial. Many noted they had discovered at least one new tool that they would continue to use.

At lower language proficiency levels, students might require more guidance to get them started, after which most would be expected to quickly become efficient at selecting and using appropriate DTs. Such guidance might include a list of DTs such as the one generated by this study (Appendix N). The results also suggest that students can benefit from support and guidance from learning communities that form as students share information about the DTs they use. Indeed, participants seemed to base their decision to use a DT largely on the recommendations of others. However, though many younger students may be considered digital natives, they may still encounter challenges with using DTs. Teachers should avoid making assumptions that all students can use digital tools easily. In fact, ease of use was reported as an especially desirable quality of a new DT.

The greatest limitation to this study is the relatively low number of participants. While the results of this study do contribute to the understanding the impact of digital devices and tools for independent English learning in Qatar and the Middle East, more research is needed. One focus of future research might consider how the needs of students of varying language ability differ. In addition to our discussion of results and their implications, we hope that the list of digital tools used by students, as well as their evaluation of them, can be of use to instructors in guiding students towards helpful tools to help achieve their English learning goals. 


\section{Appendix A. Digital Tool Project Report}

1. Reason for goal:

2. Tool used: (cut and paste the URL, or name the APP)

3. Reason for selecting this tool:

4. The tool was culturally appropriate for university students in Qatar.

1. Strongly disagree, 2. Disagree, 3. Agree, 4. Strongly Agree.

5. The tool was useful in helping me with my language goal.

1. Strongly disagree, 2. Disagree, 3. Agree, 4. Strongly Agree.

6. If the tool helped you with your goal, briefly explain how.

7. What were some other good points about the tool (if any)?

8. What were some bad points about the tool (if any)?

\section{APPENDIX B QUESTIONNAIRE 1}

\section{Digital Tools Questionnaire 1}

\begin{tabular}{|l|l|l|l|l|l|}
\hline $\begin{array}{l}\text { BNRT / } \\
\text { PDBN }\end{array}$ & Age & $\begin{array}{l}\text { Male or } \\
\text { Female }\end{array}$ & Nationality & First language & $\begin{array}{l}\text { How many years } \\
\text { in Qatar? }\end{array}$ \\
\hline & & & & & \\
\hline
\end{tabular}

\begin{tabular}{|c|c|c|c|}
\hline Device & $\begin{array}{l}\text { How many } \\
\text { devices? } \\
\text { (ex. } 0,1,2,3)\end{array}$ & $\begin{array}{c}\text { Academic Use } \\
\text { How much time a day? } \\
\text { (ex. } 15 \text { minutes, } 2 \text { hours) }\end{array}$ & $\begin{array}{l}\text { Non-Academic Use } \\
\text { How much time a day? } \\
\text { (ex. } 15 \text { minutes, } 2 \text { hours) }\end{array}$ \\
\hline \multicolumn{4}{|c|}{ Computer } \\
\hline \multicolumn{4}{|c|}{ Smart phone } \\
\hline Tablet & & & \\
\hline
\end{tabular}

\section{A digital tool is:}

Any program, app, or internet site that you use through your computer, smartphone, or tablet.

\section{Circle the best answer:}

\begin{tabular}{|c|c|c|c|}
\hline \multicolumn{4}{|c|}{ 1. I am comfortable using digital tools } \\
\hline A) Strongly agree & B) Agree & C) Disagree & D) Strongly disagree \\
\hline \multicolumn{4}{|c|}{ 2. I often use digital tools in English } \\
\hline A) Strongly agree & B) Agree & C) Disagree & D) Strongly disagree \\
\hline \multicolumn{4}{|c|}{ 3. I want to use digital tools to help me improve my English ability } \\
\hline A) Strongly agree & B) Agree & C) Disagree & D) Strongly disagree \\
\hline \multicolumn{4}{|c|}{ 4. I often use digital tools to help me improve my English ability } \\
\hline A) Strongly agree & B) Agree & C) Disagree & D) Strongly disagree \\
\hline \multicolumn{4}{|c|}{ 5. There are many digital tools to help me improve my English ability } \\
\hline A) Strongly agree & B) Agree & C) Disagree & D) Strongly disagree \\
\hline \multicolumn{4}{|c|}{ 6. I use many different kinds of digital tools to help me improve my English ability } \\
\hline A) Strongly agree & B) Agree & C) Disagree & D) Strongly disagree \\
\hline \multicolumn{4}{|c|}{ 7. I want to find new digital tools to help me improve my English ability } \\
\hline A) Strongly agree & B) Agree & C) Disagree & D) Strongly disagree \\
\hline \multicolumn{4}{|c|}{ 8. I am motivated to improve my English ability } \\
\hline A) Strongly agree & B) Agree & C) Disagree & D) Strongly disagree \\
\hline \multicolumn{4}{|c|}{ 9. I often communicate with others about how they study English } \\
\hline A) Strongly agree & B) Agree & C) Disagree & D) Strongly disagree \\
\hline
\end{tabular}


APPENDIX C. QUESTIONNAIRE 2

Digital Tool Use Questionnaire 2

\begin{tabular}{|c|c|c|c|c|c|c|c|c|c|c|}
\hline \multirow{2}{*}{$\begin{array}{l}\text { Digital tools } \\
\text { Digital tools: Any program, app, or internet site that you use } \\
\text { through your computer, smartphone, or tablet. } \\
\text { How often do you use these digital tools? Please give an answer for } \\
\text { both the blue and yellow columns. }\end{array}$} & \multicolumn{5}{|c|}{$\begin{array}{l}\text { Other than English, when I } \\
\text { use digital tools, I use }\end{array}$} & \multicolumn{5}{|c|}{ English } \\
\hline & $\begin{array}{l}\text { ळ } \\
\text { ¿ }\end{array}$ & 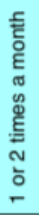 & 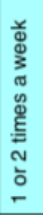 & 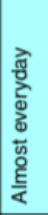 & 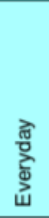 & 市 & 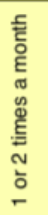 & 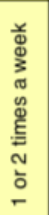 & 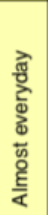 & 离 \\
\hline EXAMPLE: News & & & & $\mathrm{x}$ & & $\mathrm{x}$ & & & & \\
\hline \multicolumn{11}{|l|}{ 1. Social Media (ex. Facebook, Twitter, Instagram, Snapchat) } \\
\hline \multicolumn{11}{|l|}{ 2. Games (ex. Minecraft) } \\
\hline \multicolumn{11}{|l|}{ 3. News } \\
\hline \multicolumn{11}{|l|}{ 4. Blogs } \\
\hline \multicolumn{11}{|l|}{ 5. Religion } \\
\hline \multicolumn{11}{|l|}{ 6. Hobbies (ex. learning about photography) } \\
\hline \multicolumn{11}{|l|}{ 7. Video sharing sites (ex. You-Tube) } \\
\hline \multicolumn{11}{|l|}{ 8. Movies, television or other programs (through internet!) } \\
\hline \multicolumn{11}{|l|}{ 9. Pod casts (audio programs) } \\
\hline \multicolumn{11}{|l|}{ 10. Written communication for individuals (ex. email, sms, WhatsApp) } \\
\hline 11. Written communication for groups (ex. WhatsApp, Google groups) & & & & & & & & & & \\
\hline
\end{tabular}

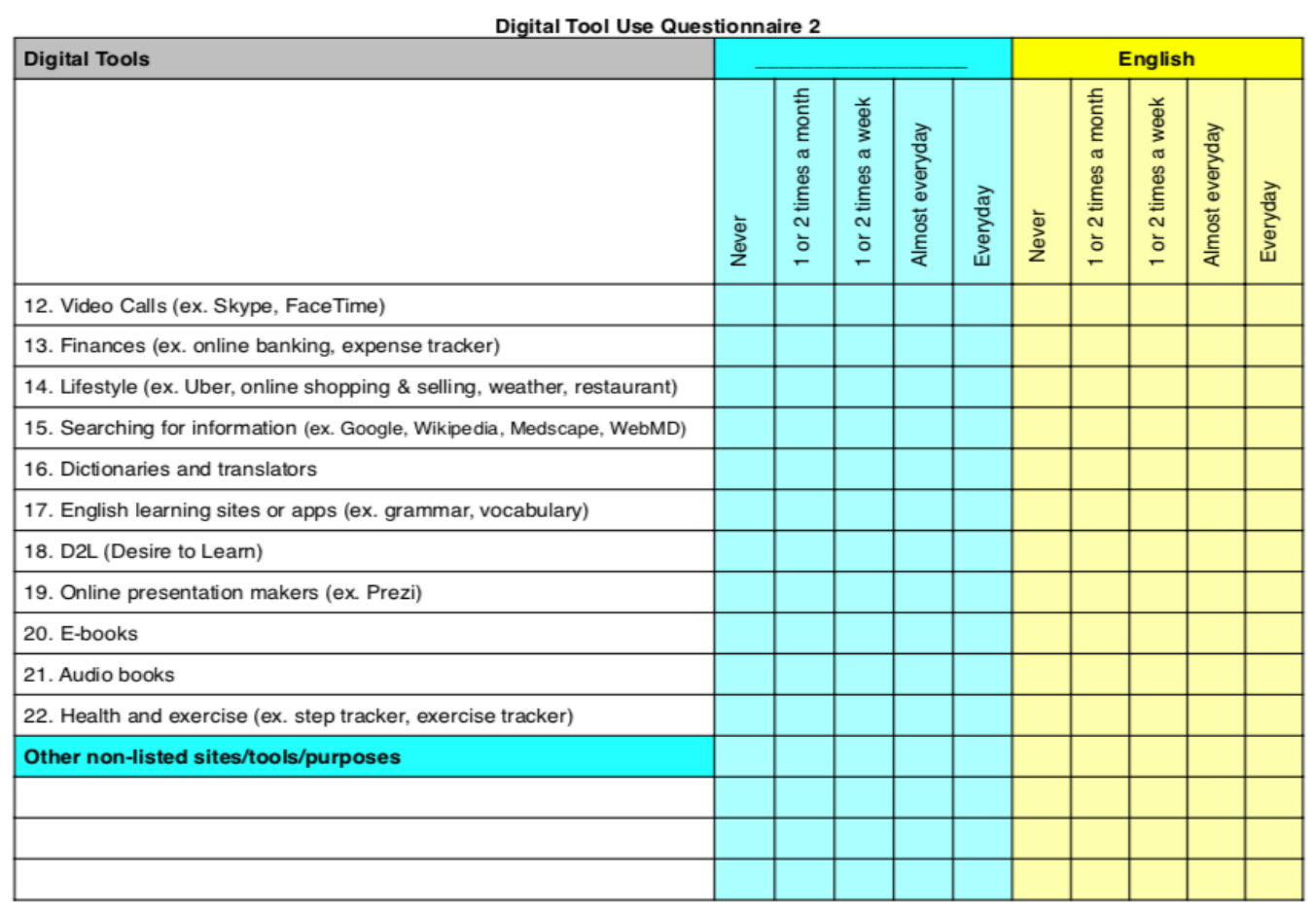

\section{APPENDIX D. Focus GRoup 1 GUIDING Questions, POST INTERVENTION}

1. How was your experience with this project? Positive or negative?

2. Did participating in the Digital Tools Project help to improve your English?

a. If yes, what aspects helped the most? The least?

b. If no, why do you think it wasn't beneficial?

3. This semester you were required to find, try out, and report on your experiences using digital tools. Tell us about your experience: 
a. finding the digital tools

i. Was it easy? Was it enjoyable? Was it helpful?

b. trialing the digital tools

i. Was it easy? Was it enjoyable? Was it helpful?

c. reporting on the digital tools

i. Was it easy? Was it enjoyable? Was it helpful?

d. did you read other people's reports on their experiences?

i. What was that like? Was it helpful?

4. Every two weeks, you had to come up with a new goal for improving your English using a digital tool. What did you think about this part of the assignment?

a. Was it easy? Was it enjoyable? Was it helpful?

b. Was anything frustrating about this part of the project?

5. Do you think you will continue to use digital tools to help improve your English in the future, now the semester is over?

IF TIME: Anything you would recommend changing

\section{Appendix E. Focus Group 2 Guiding Questions, 1 Semester Post Treatment}

1. Are you using digital tools to help you with English now?

Follow-up: How many?

Follow-up: Which ones?

2. Are you using any digital tools now that you first learned about during the assignment? (You did not already know about them before the assignment.)

Follow-up: Why not?

Follow-up: Which ones? What are you using them for?

3. Having completed the digital tool assignment, do you now feel you have more resources to improve your English on your own?

4. During the digital tool assignment, did you learn anything from other students, by talking to them, or reading their work?

Follow-up: What did you learn?

5. If you had a question about English language now, would you first try to find the answer yourself, or go to a teacher?

Follow-up: Why?

6. The data from the questionnaires indicates that people did not increase the time spent using digital tools during the digital tools assignment. Does this surprise you?

Follow-up: Why?

7. Based on the questionnaires, people did said that they felt less comfortable using digital tools following the assignment semester. Does this surprise you?

Follow-up: Why? 
Appendix F. Baseline: Number of Digital DeVices by Type

\begin{tabular}{|c|c|c|c|c|c|c|}
\hline Type & Number & Frequency & $\%$ & Cum. \% & Mean & $S D$ \\
\hline \multirow[t]{4}{*}{ Computers } & 0 & 4 & 15.4 & 15.4 & 1.19 & 0.749 \\
\hline & 1 & 14 & 53.8 & 69.2 & & \\
\hline & 2 & 7 & 26.9 & 96.2 & & \\
\hline & 3 & 1 & 3.8 & 100.0 & & \\
\hline \multirow[t]{4}{*}{ Smartphones } & 0 & 0 & 0 & 0 & 1.15 & 0.464 \\
\hline & 1 & 23 & 88.5 & 88.5 & & \\
\hline & 2 & 2 & 7.7 & 96.2 & & \\
\hline & 3 & 1 & 3.8 & 100.0 & & \\
\hline \multirow[t]{4}{*}{ Tablets } & 0 & 17 & 65.4 & 65.4 & 0.38 & 0.571 \\
\hline & 1 & 8 & 30.8 & 96.2 & & \\
\hline & 2 & 1 & 3.8 & 100.0 & & \\
\hline & 3 & 0 & 0 & 0 & & \\
\hline \multirow[t]{7}{*}{ Total Devices } & 0 & 0 & 0 & 0 & 2.73 & 1.313 \\
\hline & 1 & 3 & 11.5 & 11.5 & & \\
\hline & 2 & 12 & 46.2 & 57.7 & & \\
\hline & 3 & 4 & 15.4 & 73.1 & & \\
\hline & 4 & 4 & 15.4 & 88.5 & & \\
\hline & 5 & 2 & 7.7 & 96.2 & & \\
\hline & 6 & 1 & 3.8 & 100.0 & & \\
\hline
\end{tabular}

Appendix G. Baseline: Reported Hours Per Day of Digital Device Use by Type and Purpose

\begin{tabular}{lllllll}
\hline Type & Purpose & $N$ & Min. & Max. & Mean & $S D$ \\
\hline Computers & Academic & 26 & 0 & 4.50 & 1.11 & 1.123 \\
& Non-academic & 26 & 0 & 14.50 & 1.85 & 3.690 \\
Smartphones & Academic & 26 & 0 & 3.00 & 1.34 & 1.161 \\
& Non-academic & 26 & 0.25 & 16.00 & 6.11 & 5.160 \\
Tablets & Academic & 26 & 0 & 4.50 & 0.32 & 0.998 \\
& Non-academic & 26 & 0 & 5.00 & 0.47 & 1.368 \\
Valid N (listwise) & & 26 & & & \\
\hline
\end{tabular}

ApPendix H. BASEline: Reported AtTitudes Regarding Digital ToOls, Learning English, and Digital ToOL USE FOR LEARNING ENGLISH

\begin{tabular}{llll}
\hline & $N$ Min.Max. $\bar{X} S D$ \\
\hline I am comfortable using digital tools & 261 & 3 & 1.19 .491 \\
I often use digital tools in English & 261 & 3 & 1.81 .634 \\
I want to use digital tools to help me improve my English & 261 & 2 & 1.35 .485 \\
I often use digital tools to help me improve my English ability & 261 & 4 & 1.73 .724 \\
There are many digital tools to help me improve my English ability & 261 & 3 & 1.54 .647 \\
I use many different kinds of digital tools to help me improve my English ability 251 & 3 & 1.76 .523 \\
I want to find new digital tools to help me improve my English ability & 261 & 3 & 1.54 .582 \\
I am motivated to improve my English ability & 261 & 2 & 1.31 .471 \\
I often communicate with others about how they study English & 261 & 3 & 2.00 .800 \\
Valid N (listwise) & 26 & & \\
\hline
\end{tabular}

Questionnaire scale: 1 = strongly agree, 2 = agree, $3=$ disagree, $4=$ strongly disagree 
ApPendix I. Baseline: Reported Use of Digital Tools for Specific Purposes - In L1 AND IN ENGlish

\begin{tabular}{|c|c|c|c|c|c|c|c|c|c|c|c|c|c|}
\hline \multirow[b]{2}{*}{ Function } & \multicolumn{5}{|c|}{ In L1 } & \multicolumn{5}{|c|}{ In English } & \multicolumn{3}{|c|}{ Paired t-tests } \\
\hline & $N$ & Min. & Max. & $\bar{X}$ & $S D$ & $N$ & Min. & Max. & $\bar{X}$ & $S D$ & $t$ & $d f$ & $p$ \\
\hline Social Media & 24 & 0 & 4 & 2.79 & 1.503 & 25 & 0 & 4 & 2.64 & 1.186 & 0.424 & 22 & .68 \\
\hline Games & 24 & 0 & 4 & 1.17 & 1.435 & 25 & 0 & 4 & 2.04 & 1.485 & -1.647 & 22 & .11 \\
\hline News & 24 & 0 & 4 & 1.87 & 1.541 & 25 & 0 & 4 & 1.08 & 1.115 & 3.867 & 22 & .00 \\
\hline Blogs & 24 & 0 & 4 & 1.46 & 1.474 & 25 & 0 & 3 & 1.12 & 1.054 & 1.594 & 22 & .13 \\
\hline Religion & 24 & 0 & 4 & 2.08 & 1.472 & 25 & 0 & 2 & .44 & .712 & 5.334 & 22 & .00 \\
\hline Hobbies & 24 & 0 & 4 & 1.96 & 1.459 & 25 & 0 & 4 & 1.60 & 1.258 & 0.927 & 22 & .36 \\
\hline Video Sharing sites & 24 & 0 & 4 & 2.21 & 1.179 & 25 & 0 & 4 & 2.00 & 1.291 & 1.232 & 22 & .23 \\
\hline $\begin{array}{l}\text { Movies, TV, etc., } \\
\text { online }\end{array}$ & 24 & 0 & 4 & 1.92 & 1.248 & 25 & 1 & 4 & 2.36 & 1.036 & -1.751 & 22 & .09 \\
\hline Podcasts & 24 & 0 & 4 & 1.75 & 1.7 & 25 & 0 & 4 & 1.20 & 1.443 & 1.348 & 22 & .19 \\
\hline $\begin{array}{l}\text { Written } \\
\text { communication for } \\
\text { individuals }\end{array}$ & 24 & 0 & 4 & 3.00 & 1.351 & 25 & 0 & 4 & 2.68 & 1.406 & 1.288 & 22 & .21 \\
\hline $\begin{array}{l}\text { Written } \\
\text { communication for } \\
\text { groups }\end{array}$ & 24 & 0 & 4 & 2.96 & 1.334 & 25 & 0 & 4 & 2.48 & 1.531 & 1.692 & 22 & .10 \\
\hline Video Calls & 24 & 0 & 4 & 1.54 & 1.56 & 24 & 0 & 4 & 1.00 & 1.383 & 1.609 & 21 & .12 \\
\hline Finances & 24 & 0 & 4 & 0.71 & 1.367 & 24 & 0 & 4 & .71 & 1.197 & 0.000 & 21 & 1.0 \\
\hline Lifestyle & 24 & 0 & 3 & 0.92 & 1.018 & 24 & 0 & 4 & 1.79 & 1.414 & -2.932 & 21 & .01 \\
\hline $\begin{array}{ll}\text { Searching } & \text { for } \\
\text { Information } & \\
\end{array}$ & 24 & 0 & 4 & 2.88 & 1.116 & 24 & 0 & 4 & 2.54 & 1.250 & 1.449 & 21 & .16 \\
\hline $\begin{array}{l}\text { Dictionaries and } \\
\text { Translators }\end{array}$ & 24 & 0 & 4 & 2.25 & 1.452 & 24 & 0 & 4 & 3.38 & 0.924 & -4.688 & 21 & .00 \\
\hline $\begin{array}{l}\text { English learning } \\
\text { sites or apps }\end{array}$ & 24 & 0 & 4 & 1.04 & 1.459 & 24 & 0 & 4 & 2.67 & 1.129 & -6.236 & 21 & .00 \\
\hline $\begin{array}{l}\text { Online Presentation } \\
\text { Makers }\end{array}$ & 23 & 0 & 4 & 0.52 & 1.201 & 23 & 0 & 4 & .87 & 1.359 & -2.121 & 20 & .05 \\
\hline E-books & 24 & 0 & 4 & 0.75 & 1.294 & 24 & 0 & 4 & .75 & 1.189 & 0.000 & 21 & 1.0 \\
\hline Audiobooks & 24 & 0 & 4 & 0.37 & 0.924 & 24 & 0 & 3 & .33 & 0.761 & 0.568 & 21 & .58 \\
\hline Health and exercise & 24 & 0 & 2 & 0.83 & 0.868 & 24 & 0 & 4 & 1.46 & 1.285 & -2.592 & 21 & .02 \\
\hline Valid N (listwise) & 22 & & & & & 22 & & & & & & & \\
\hline
\end{tabular}

Questionnaire scale: $0=$ never, $1=$ once or twice a month, $2=$ once or twice a week, $3=$ almost every day, $4=$ every day

\section{Appendix J. Post-test Means and AnCOVA Results for Hours Per Day of Digital Device Use By Group}

\begin{tabular}{lllllllll}
\hline & \multicolumn{3}{l}{ Means, adjusted for Pre-Test differences } & \multicolumn{3}{l}{ ANCOVA Results } \\
\hline & \multicolumn{2}{l}{ Control } & \multicolumn{2}{l}{ Treatment } & \multicolumn{1}{l}{ T-C } & & \\
\hline & $n$ & $\bar{X}$ & $n$ & $\bar{X}$ & & $F$ & $p$ & $\eta_{p}{ }^{2}$ \\
\hline Total Digital Device Use Academic Purposes & 9 & 3.517 & 17 & 2.76 & -0.757 & 0.934 & .344 & .039 \\
Total Digital Device Use Non-Academic Purposes & 9 & 7.372 & 17 & 4.734 & -2.638 & 2.249 & .147 & .089 \\
Computer Use Academic Purposes & 9 & 1.390 & 17 & 1.044 & -0.346 & 0.950 & .340 & .040 \\
Computer Use Non-Academic Purposes & 9 & 1.009 & 17 & 1.157 & 0.148 & 0.113 & .740 & .005 \\
Smartphone Use Academic Purposes & 9 & 1.774 & 17 & 1.094 & -0.680 & 2.062 & .164 & .082 \\
Smartphone Use Non-Academic Purposes & 9 & 5.807 & 17 & 3.386 & -2.421 & 2.553 & .124 & .100 \\
Tablet Use Academic Purposes & 9 & 0.321 & 17 & 0.639 & 0.318 & 0.349 & .561 & .015 \\
Tablet Use Non-Academic Purposes & 9 & 0.298 & 17 & 0.313 & 0.015 & 0.003 & .954 & .000 \\
\hline
\end{tabular}

ApPENDix K. Follow-up MeAns ANd ANCOVA Results for Digital DeVice Use by Group

\begin{tabular}{|c|c|c|c|c|c|c|c|c|}
\hline & \multicolumn{5}{|c|}{ Means, adjusted for Pre-Test differences } & \multicolumn{3}{|c|}{ ANCOVA Results } \\
\hline & \multicolumn{2}{|c|}{ Control } & \multicolumn{2}{|c|}{ Treatment } & \multirow[t]{2}{*}{$\mathrm{T}-\mathrm{C}$} & & & \\
\hline & $n$ & $\bar{X}$ & $n$ & $\bar{X}$ & & $F$ & $p$ & $\eta_{p}^{2}$ \\
\hline Total Digital Device Use Academic Purposes & 9 & 3.517 & 17 & 2.76 & -0.757 & 0.934 & .344 & .039 \\
\hline Total Digital Device Use Non-Academic Purposes & 9 & 7.372 & 17 & 4.734 & -2.638 & 2.249 & .147 & .089 \\
\hline Computer Use Academic Purposes & 9 & 1.390 & 17 & 1.044 & -0.346 & 0.950 & .340 & .040 \\
\hline Computer Use Non-Academic Purposes & 9 & 1.009 & 17 & 1.157 & 0.148 & 0.113 & .740 & .005 \\
\hline Smartphone Use Academic Purposes & 9 & 1.774 & 17 & 1.094 & -0.680 & 2.062 & .164 & .082 \\
\hline Smartphone Use Non-Academic Purposes & 9 & 5.807 & 17 & 3.386 & -2.421 & 2.553 & .124 & .100 \\
\hline Tablet Use Academic Purposes & 9 & 0.321 & 17 & 0.639 & 0.318 & 0.349 & .561 & .015 \\
\hline Tablet Use Non-Academic Purposes & 9 & 0.298 & 17 & 0.313 & 0.015 & 0.003 & .954 & .000 \\
\hline
\end{tabular}


Appendix L. Post-test Means and AnCOVA Results for Digital Tool Use Attitudes and Behaviours

\begin{tabular}{lllllllll}
\hline & \multicolumn{3}{l}{ Means, adjusted for Pre-Test differences } & \multicolumn{2}{l}{ ANCOVA Results } \\
\hline & \multicolumn{2}{l}{ Control } & \multicolumn{2}{l}{ Treatment } & \multicolumn{1}{l}{ T-C } & & \\
\hline & $n$ & $\bar{X}$ & $n$ & $\bar{X}$ & & $F$ & $p$ & $\eta_{p}{ }^{2}$ \\
\hline Total Digital Device Use Academic Purposes & 9 & 3.517 & 17 & 2.76 & -0.757 & 0.934 & .344 & .039 \\
Total Digital Device Use Non-Academic Purposes & 9 & 7.372 & 17 & 4.734 & -2.638 & 2.249 & .147 & .089 \\
Computer Use Academic Purposes & 9 & 1.390 & 17 & 1.044 & -0.346 & 0.950 & .340 & .040 \\
Computer Use Non-Academic Purposes & 9 & 1.009 & 17 & 1.157 & 0.148 & 0.113 & .740 & .005 \\
Smartphone Use Academic Purposes & 9 & 1.774 & 17 & 1.094 & -0.680 & 2.062 & .164 & .082 \\
Smartphone Use Non-Academic Purposes & 9 & 5.807 & 17 & 3.386 & -2.421 & 2.553 & .124 & .100 \\
Tablet Use Academic Purposes & 9 & 0.321 & 17 & 0.639 & 0.318 & 0.349 & .561 & .015 \\
Tablet Use Non-Academic Purposes & 9 & 0.298 & 17 & 0.313 & 0.015 & 0.003 & .954 & .000 \\
\hline
\end{tabular}

Appendix M. Follow-up MEAns And ANCOVA Results for Digital ToOl Use Attitudes ANd Behaviours

\begin{tabular}{|c|c|c|c|c|c|c|c|c|}
\hline & \multicolumn{5}{|c|}{ Means, adjusted for Pre-Test differences } & \multicolumn{3}{|c|}{ ANCOVA Results } \\
\hline & \multicolumn{2}{|c|}{ Control } & \multicolumn{2}{|c|}{ Treatment } & \multirow[t]{2}{*}{$\mathrm{T}-\mathrm{C}$} & & & \\
\hline & $n$ & $\bar{X}$ & $n$ & $\bar{X}$ & & $F$ & $p$ & $\eta_{p}^{2}$ \\
\hline I am comfortable using digital tools & 9 & 1.335 & 16 & 1.249 & -0.086 & 0.187 & .669 & .008 \\
\hline I often use digital tools in English & 9 & 1.894 & 16 & 1.497 & -0.397 & 2.910 & .102 & .117 \\
\hline I want to use digital tools to help me improve my English & 9 & 1.563 & 16 & 1.433 & -0.130 & 0.381 & .544 & .017 \\
\hline I often use digital tools to help me improve my English ability & 9 & 1.601 & 16 & 1.725 & 0.124 & 0.302 & .588 & .014 \\
\hline There are many digital tools to help me improve my English ability & 9 & 2.065 & 16 & 1.526 & -0.539 & 3.289 & .083 & .130 \\
\hline I use many different kinds of digital tools to help me improve my English ability & 8 & 1.799 & 16 & 1.663 & -0.136 & 0.181 & .675 & .009 \\
\hline I want to find new digital tools to help me improve my English ability & 9 & 1.666 & 16 & 1.875 & 0.209 & 0.734 & .401 & .032 \\
\hline I am motivated to improve my English ability & 9 & 1.667 & 15 & 1.467 & -0.200 & 1.074 & .312 & .049 \\
\hline I often communicate with others about how they study English & 9 & 1.964 & 16 & 2.020 & 0.056 & 0.040 & .843 & .002 \\
\hline
\end{tabular}

Appendix N. Post-test Means and ANCOVA Results for Digital ToOl Use for Specific Functions - In ENGLISH

\begin{tabular}{|c|c|c|c|c|c|c|c|c|}
\hline & \multicolumn{5}{|c|}{ Means, adjusted for Pre-Test differences } & \multicolumn{3}{|c|}{ ANCOVA Results } \\
\hline & \multicolumn{2}{|c|}{ Control } & \multicolumn{2}{|c|}{ Treatment } & \multirow[t]{2}{*}{$\mathrm{T}-\mathrm{C}$} & & & \\
\hline & $n$ & $\bar{X}$ & $n$ & $\bar{X}$ & & $F$ & $p$ & $\eta_{p}{ }^{2}$ \\
\hline Social Media & 9 & 3.065 & 16 & 2.963 & -0.102 & 0.051 & .824 & .002 \\
\hline Games & 9 & 1.504 & 16 & 2.154 & 0.65 & 1.096 & .306 & .047 \\
\hline News & 8 & 0.706 & 16 & 1.21 & 0.504 & 2.039 & .168 & .089 \\
\hline $\mathrm{B} \log s$ & 9 & 1.343 & 15 & 1.794 & 0.451 & 0.671 & .422 & .031 \\
\hline Religion & 8 & 0.625 & 16 & 0.75 & 0.125 & 0.105 & .749 & .005 \\
\hline Hobbies & 9 & 1.365 & 16 & 1.795 & 0.430 & 0.936 & .344 & .041 \\
\hline Video sharing sites (ex. YouTube) & 9 & 1.901 & 16 & 2.18 & 0.279 & 0.389 & .539 & .017 \\
\hline Movies, television, or other programs (through internet) & 8 & 2.553 & 15 & 2.371 & -0.182 & 0.206 & .655 & .010 \\
\hline Podcasts & 9 & 1.315 & 15 & 0.678 & -0.637 & 1.495 & .235 & .066 \\
\hline Written communication for individuals (ex. Email, SMS, WhatsApp) & 9 & 2.785 & 16 & 2.746 & -0.039 & 0.009 & .926 & .000 \\
\hline Written communication for groups (ex. WhatsApp, Google Groups) & 9 & 2.21 & 16 & 2.444 & 0.234 & 0.292 & .594 & .013 \\
\hline Video Calls (ex. Slype, FaceTime) & 9 & 2.26 & 15 & 1.377 & -0.883 & 3.039 & .096 & .126 \\
\hline Finances (ex. Online banking, expense tracker) & 9 & 1.725 & 15 & 1.298 & -0.427 & 0.571 & .458 & .026 \\
\hline Lifestyle (ex. Uber, online shopping \& selling, weather, restaurant) & 9 & 1.939 & 15 & 2.036 & 0.097 & 0.021 & .886 & .001 \\
\hline Searching for information (ex. Google, Wikipedia, Medscape, WebMD) & 9 & 2.325 & 15 & 2.805 & 0.480 & 1.122 & .302 & .051 \\
\hline Dictionaries and translators & 9 & 2.927 & 15 & 2.844 & -0.083 & 0.03 & .863 & .001 \\
\hline English learning sites or apps (ex. Grammar, vocabulary) in L1* & 7 & 0.565 & 14 & 1.289 & 0.724 & 1.054 & .318 & .055 \\
\hline English learning sites or apps in English & 9 & 3.139 & 15 & 2.517 & -0.622 & 2.874 & .105 & .120 \\
\hline D2L (Desire to Learn) & 9 & 2.927 & 15 & 2.844 & -0.083 & 0.03 & .863 & .001 \\
\hline Online presentation makers (ex. Prezi) & 8 & 1.455 & 15 & 1.024 & -0.431 & 0.859 & .365 & .041 \\
\hline e-books & 9 & 0.898 & 15 & 0.995 & 0.097 & 0.06 & .809 & .003 \\
\hline Audio books & 9 & 0.938 & 15 & 0.571 & -0.367 & 0.582 & .454 & .027 \\
\hline Health and exercise (ex. Step tracker, exercise tracker) & 9 & 1.895 & 15 & 1.396 & -0.499 & 1.162 & .293 & .052 \\
\hline Mean use for all functions & 7 & 1.819 & 11 & 1.826 & 0.007 & 0.002 & .970 & .000 \\
\hline
\end{tabular}




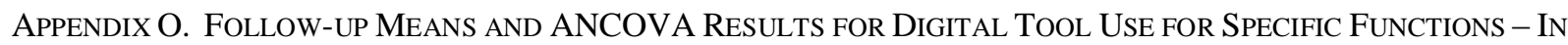
ENGLISH

\begin{tabular}{|c|c|c|c|c|c|c|c|c|}
\hline & \multicolumn{5}{|c|}{ Means, adjusted for Pre-Test differences } & \multicolumn{3}{|c|}{ ANCOVA Results } \\
\hline & \multicolumn{2}{|c|}{ Control } & \multicolumn{2}{|c|}{ Treatment } & \multirow[t]{2}{*}{$\mathrm{T}-\mathrm{C}$} & & & \\
\hline & $n$ & $\bar{X}$ & $n$ & $\bar{X}$ & & $F$ & $p$ & $\eta_{p}{ }^{2}$ \\
\hline Social Media & 9 & 2.806 & 16 & 2.984 & 0.179 & 0.126 & .725 & .006 \\
\hline Games & 9 & 1.204 & 16 & 1.761 & 0.557 & 0.869 & .361 & .038 \\
\hline News & 9 & 1.883 & 15 & 1.070 & -0.813 & 2.435 & .134 & .104 \\
\hline $\mathrm{B} \log \mathrm{s}$ & 9 & 1.439 & 16 & 1.128 & -0.311 & 0.374 & .547 & .017 \\
\hline Religion & 9 & .957 & 16 & .774 & -0.182 & 0.124 & .728 & .006 \\
\hline Hobbies & 9 & 1.687 & 16 & 1.551 & -0.135 & 0.114 & .738 & .005 \\
\hline Video sharing sites (ex. YouTube) & 9 & 2.152 & 16 & 2.164 & 0.012 & 0.000 & .985 & .000 \\
\hline Movies, television, or other programs (through internet) & 9 & 1.944 & 16 & 2.656 & 0.712 & 2.086 & .163 & .087 \\
\hline Podcasts & 9 & .962 & 16 & 1.022 & 0.060 & 0.010 & .921 & .000 \\
\hline Written communication for individuals (ex. Email, SMS, WhatsApp) & 9 & 2.894 & 16 & 2.560 & -0.334 & 0.361 & .554 & .016 \\
\hline Written communication for groups (ex. WhatsApp, Google Groups) & 9 & 2.970 & 16 & 2.517 & -0.453 & 0.705 & .410 & .031 \\
\hline Video Calls (ex. Slype, FaceTime) & 9 & 1.701 & 15 & 1.180 & -0.521 & 1.217 & .282 & .055 \\
\hline Finances (ex. Online banking, expense tracker) & 8 & .999 & 15 & 1.067 & 0.069 & 0.018 & .894 & .001 \\
\hline Lifestyle (ex. Uber, online shopping \& selling, weather, restaurant) & 9 & 1.767 & 14 & 1.328 & -0.439 & 0.929 & .347 & .044 \\
\hline Searching for information (ex. Google, Wikipedia, Medscape, WebMD) & 9 & 2.970 & 15 & 2.818 & -0.151 & 0.159 & 694 & .008 \\
\hline Dictionaries and translators & 9 & 2.890 & 15 & 2.933 & 0.042 & 0.007 & .932 & .000 \\
\hline English learning sites or apps (ex. Grammar, vocabulary) in L1* & 8 & .995 & 13 & 1.080 & 0.084 & 0.018 & .894 & .001 \\
\hline English learning sites or apps in English & 9 & 2.758 & 14 & 2.084 & -0.674 & 1.325 & .263 & .062 \\
\hline D2L (Desire to Learn) & 8 & 2.620 & 15 & 3.469 & 0.849 & 2.480 & .131 & .110 \\
\hline Online presentation makers (ex. Prezi) & 8 & 2.172 & 15 & .842 & -1.330 & 1.176 & .291 & .056 \\
\hline e-books & 9 & 1.763 & 15 & 1.275 & -0.488 & 0.609 & .444 & .028 \\
\hline Audio books & 9 & .833 & 15 & .833 & 0.000 & 0.000 & 1.000 & .000 \\
\hline Health and exercise (ex. Step tracker, exercise tracker) & 9 & 1.601 & 15 & 2.106 & .505 & 0.957 & .339 & .044 \\
\hline Mean use for all functions & 6 & 2.001 & 10 & 1.695 & -0.306 & 1.241 & .285 & .087 \\
\hline
\end{tabular}

* Item appeared on the L1 list for DT use for specific functions

APPENDix P. STUDENT RATINGS OF Digital ToOLS

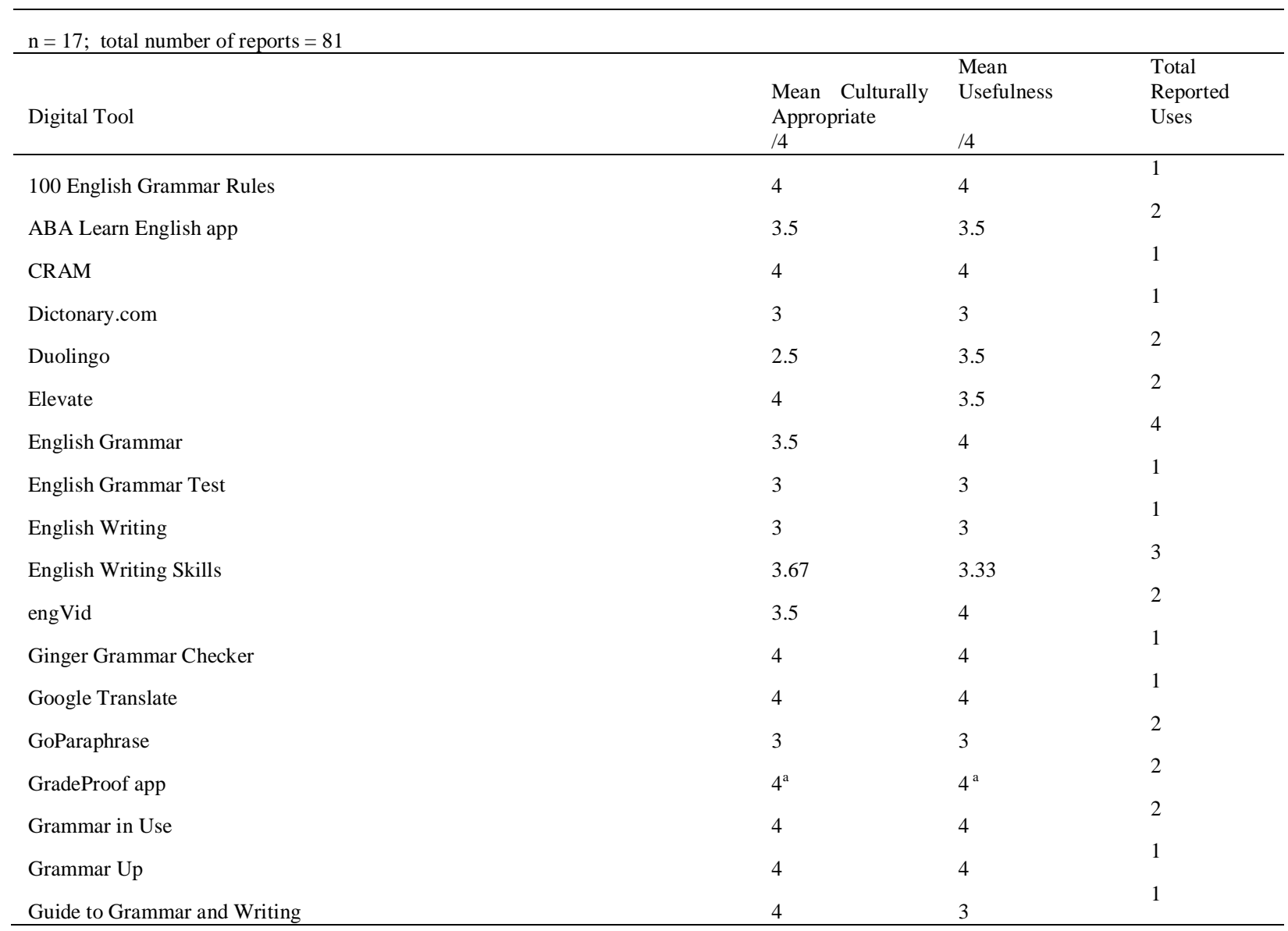




\begin{tabular}{|c|c|c|c|}
\hline Grammarly & 4 & 4 & 1 \\
\hline Grammarly Keyboard & 4 & 4 & 1 \\
\hline Hello English: Learn English & 3 & 3 & 3 \\
\hline IELTS Writing & $4^{\mathrm{b}}$ & 3.5 & 4 \\
\hline IXL Learning & 4 & 4 & 1 \\
\hline Johnny Grammar Word Challenge & 4 & 4 & 1 \\
\hline Kahoot & 3 & 3 & 1 \\
\hline Learn English Grammar & $4^{\mathrm{a}}$ & $4^{\mathrm{a}}$ & 2 \\
\hline Learn English Grammar Rules & 4 & 4 & 1 \\
\hline Learn English Vocabulary - 6,000 Words & 4 & 4 & 1 \\
\hline Learn American English Online & 1 & 3 & 1 \\
\hline Ling Ling English & 2.5 & 4 & 2 \\
\hline Magooosh & 3 & 3 & 1 \\
\hline Memrise & 3.5 & 3.5 & 2 \\
\hline Merriam Webster Dictionary & 4 & 4 & 2 \\
\hline Oxford English Dictionary & 3 & 3 & 1 \\
\hline Perfect English Grammar & 4 & 3 & 1 \\
\hline Quizlet & 4 & 4 & 1 \\
\hline RoadToGrammar.com & 4 & 4 & 1 \\
\hline Speak - Text to Speech & 3 & 4 & 1 \\
\hline Speak and Translate & 4 & 3 & 1 \\
\hline Speaking Pal & 4 & 3 & 1 \\
\hline Speed Reading & 4 & 4 & 1 \\
\hline Speedy English Grammar & $3^{\mathrm{a}}$ & $4^{\mathrm{a}}$ & 2 \\
\hline SpellBoy & no response & no response & 1 \\
\hline Speller - Spell Checker & 4 & 3 & 1 \\
\hline St. Petersburg College Libraries & 3.5 & 3.5 & 2 \\
\hline Study.com & 3 & 4 & 1 \\
\hline Study.com app & 4 & 4 & 1 \\
\hline Train Your Brain English Comprehension & 4 & 3 & 1 \\
\hline Translate.com & 4 & 3 & 1 \\
\hline University of Victoria English Language Centre Study Zone & 1 & 1 & 1 \\
\hline Vocab Genius & 4 & 4 & 1 \\
\hline Vocabulary Builder & 4 & 3.5 & 2 \\
\hline Vocabulary.com & 4 & 4 & 1 \\
\hline Total Mean for All Digital Tools & 3.54 & 3.56 & \\
\hline
\end{tabular}

${ }^{a}$ only one student response

${ }^{\mathrm{b}}$ only three student responses

\section{ACKNOWLEDGEMENTS}

This publication was made possible by UREP grant \# 20-007-6-002 from the Qatar National Research Fund (a member of Qatar Foundation). The findings achieved herein are solely the responsibility of the authors. 


\section{REFERENCES}

[1] Akbar, F. (2013). What affects students' acceptance and use of technology? A test of UTAUT in the context of a higher education institution in Qatar. [Unpublished senior honors thesis]. Carnegie Mellon University. Retrieved July 26, 2020, from https://pdfs.semanticscholar.org/1ab8/0a44a26e2d09ae0dc3729be409730a782910.pdf

[2] Alajmi, M. (2011). Modeling Student Perception of Web 2.0 Technologies Adoption in Kuwait [Unpublished doctoral dissertation]. University of North Texas. Retrieved July 26, 2020, from https://digital.library.unt.edu/ark:/67531/metadc67955/.

[3] Antenos-Conforti, E. (2009). Microblogging on Twitter: social networking in intermediate Italian classes. In L. Lomicka \& G. Lord (Eds.). The next generation: Social networking and online collaboration in foreign language learning, Calico Monograph Series, No. 9. (pp. 59-90). Calico.

[4] Blake, R. J. (2013). Brave new digital classroom: Technology and foreign language learning. Georgetown University Press.

[5] Borau, K., Ullrich, C., Feng, J., \& Shen, R. (2009). Microblogging for language learning: Using twitter to train communicative and cultural competence. In M. Spaniol, Q. Li, Klamma, R., \& Lau, R. W. H. (Eds.), Advances in web-based learning (pp. 7887). Springer.

[6] Castrillo de Larreta-Azelain, M. D. (2013). Learners' attitude toward collaborative writing in e-language learning classes: A twitter project for German as a foreign language. Revista Española De Lingüística Aplicada, 26, 127-138. Retrieved July 26, 2020 , from

com.ezproxy.lib.ucalgary.ca/ps/i.do?p=AONE\&u=ucalgary\&id=GALE\%7CA364197246\&v=2.1\&it=r. https://go-gale-

[7] Central Intelligence Agency. (2016). The world factbook: Middle East: Qatar. Retrieved July 26, 2020 from https://www.cia.gov/library/publications/the-world-factbook/geos/qa.html.

[8] Chavoshi, A., \& Hamidi, H. (2019). Social, individual, technological and pedagogical factors influencing mobile learning acceptance in higher education: A case from Iran. Telematics and Informatics, 38, 113-165. https://doi.org/10.1016/j.tele.2018.09.007.

[9] Fayed, I., Yacoub, A., \& Hussein, A. (2013). Exploring the impact of using tablet devices in enhancing students listening and speaking skills in tertiary education. Proceedings of the World Conference on Mobile and Contextual Learning (mLearn), 2013(3), 1. https://doi.org/10.5339/qproc.2013.mlearn.1.

[10] International Society for Technology in Education. (2016). ISTE standards for students. Retrieved July 26, 2020, from https://id.iste.org/docs/standards-resources/iste-standards_students-2016_one-sheet_final.pdf.

[11] International Society for Technology in Education. (2017). ISTE standards for educators. Retrieved July 26, 2020, from https://hope.edu/academics/education/resources/Refreshed\%20ISTE\%20Standards\%20for\%20Educators\%20-

Permitted\%20Educational\%20Use.pdf.

[12] Lord, G., \& Lomicka, L. (2011). Calling on educators: Paving the way for the future of technology and CALL. In N. Arnold \& L. Ducate (Eds.), Present and future promises of CALL: From theory and research to new directions in language teaching ( $2^{\text {nd }}$ ed., pp. 441-469). The Computer Assisted Language Instruction Consortium.

[13] MacLeod, C. (2015). iPads in the classroom: Trials in a technical college in Qatar. Learning and Teaching in Higher Education: Gulf Perspectives, 12(1). Retrieved July 26, 2020, from http://lthe.zu.ac.ae/index.php/lthehome/article/view/170/127.

[14] Moore, M. G. (1973). Toward a theory of independent learning and teaching. The Journal of Higher Education, 44(9), 661-679. https:doi.org/10.1080/00221546.1973.11776906.

[15] Ohashi, L. (2015, November 20-23). Enriching independent learning with digital tools. [Presentation]. Japanese Association for Language Teaching (JALT) Conference 2015, Shizuoka, Japan.

[16] Ohashi, L. (2019). Using digital technology for autonomous, out-of-class English Language Learning: the influence of teacher support at a Japanese university [Doctoral thesis]. Charles Sturt University. Retrieved March 22, 2020, from https://researchoutput.csu.edu.au/en/publications/using-digital-technology-for-autonomous-out-of-class-englishlang?fbclid=IwAR21UAyeLrk9fxTDvs3pwV4XcU11WYfeBDaBNjsZSKAxHO3-p9qS1a-rfTo.

[17] Saxena, S. (2013). How technology supports self-directed learning. Ed Tech Review. Retrieved July 26, 2020, from http://edtechreview.in/news/824-how-technology-supports-self-directed-learning.

[18] Schmidt, C. (2004). The analysis of semi-structured interviews. In U. Flick, E. von Kardorff, \& I. Steinke (Eds.), A companion to qualitative research (pp. 253-258). Sage.

[19] Venkatesh, V., Morris, M., Davis, G., \& Davis, F. (2003). User acceptance of information technology: Toward a unified view. MIS Quarterly, 27(3), 425-478. https:/doi.org/10.2307/30036540.

[20] Wang, S., \& Vásquez, C. (2012). Web 2.0 and second language learning: What does the research tell us? CALICO Journal, 29(3), 412-430. Retrieved July 26, 2020, from https://www-jstororg.ezproxy.lib.ucalgary.ca/stable/pdf/calicojournal.29.3.412.pdf.

Marie-Claude Toriida holds an MAT (ESOL) from the School for International Training. Marie-Claude is an EAP faculty at the University of Calgary in Qatar. Her research interests include corpora development, corpora-based vocabulary teaching, and the use of digital tools for vocabulary learning. 
Robert Johnson holds a PhD in Applied Linguistics from Macquarie University and received the 2013 TOEFL Dissertation Award. His research interests include assessment, test validation, and (mis)communication in medical contexts and he has published in a variety of international journals, such as Assessing Writing and TESOL Quarterly.

Simon Heslup holds an MA in TEAL and an MEd in Learning Technologies. Simon is an EAP instructor at the University of Calgary in Qatar. His research interests include technology enhanced language learning and approaches and strategies for supporting teachers in the use of technology for educational purposes.

Rabeena Abdul Latif is a registered staff nurse at Hamad Medical Corporation. She graduated from the University of Calgary in 2018. Her passion is nursing, providing high quality care to patients by applying evidence based nursing practice, and being involved in different research projects.

Concita Fatima Chiuco is currently a second-year medical student in the Philippines. Equipped with her nursing background, she is furthering her education to become a physician that can provide holistic care and serve her home country. In her free time, she does volunteer work with a medical organization.

Abdul Rahman Hamdeh is a newly graduated nurse. He is passionate about research since he was in high school. He believes that research is the best way to improve practice. Adding to that, he would like to merge nursing with research skills and ex perience to improve patients' outcome in the future.

Sharifat Atinuke Makinde is a registered nurse in the Middle East. She earned her BN degree at the University of Calgary in Qatar where she graduated with the highest distinction. Her interests in research developed early as a student and she has since been involved in multiple research projects.

Rubeena Toufiq is a registered general nurse. She graduated from the University of Calgary in Qatar in 2019 and is currently working as a pediatric nurse in Qatar. Her interests include patient advocacy and research.

Nooreh Mehdi Zadeh graduated with distinction with a bachelor of nursing degree from University of Calgary in Qatar. She is a registered nurse working in the Middle East region. Her work experience includes variety of specialties. Her interests are research, medical science and psychiatry. Mental health and recent studies in cognitive neuroscience of human social behaviors are her favorite subjects for research activities. 